www.jmscr.igmpublication.org Impact Factor 5.244

Index Copernicus Value: 5.88 ISSN (e)-2347-176x ISSN (p) 2455-0450 crossref DOI: _http://dx.doi.org/10.18535/jmscr/v4i6.12

\title{
Comparative Study of Ascorbic Acid Status in Normal Pregnant and Non Pregnant Women of Udaipur
}

\author{
Author
}

Dr Deepa Singh

Department of Biochemistry, American International Institute of Medical Sciences, Udaipur

Corresponding Author

Dr Deepa Singh

Email:dc_deepa@rediffmail.com,sdeepa2910@yahoo.in

\begin{abstract}
This study is aimed to analyse serum concentration of ascorbic acid in normal pregnant and non pregnant women. A total number of 200 women, out of which 150 were pregnant with 50 number in each trimester and 50 non pregnant from Udaipur city were selected for the study. They were in the age ranging from 20-35 years. The study was conducted for a period of 9 months. Women were divided into four categories $A, B, C$ and D. Category A, B and $C$ included pregnant women of first, second and third trimester while category $D$ included non pregnant women. Average total Vitamin $C$ concentration in the first trimester was $43.6 \%$ less than the control group. Similarly, total Vitamin C concentration in the second trimester was $60 \%$ less than the control and in the third trimester it was $77.6 \%$ less than the control. In all the completed trimesters, there is significant reduction in values of vitamin $C$ than control non pregnant group ( $p$ value $<0.05$ ).

Therefore, supplementation of Vitamin $C$ during the entire period of pregnancy is recommended in order to avoid the complications associated with Vitamin $C$ deficiency during pregnancy.

Key words: Ascorbic Acid, Vitamin C, antioxidant, free radicals
\end{abstract}

\section{Introduction}

Physiologically, the mother becomes almost a new person during the period of pregnancy. Profound local and systemic changes in maternal physiology are initiated by conception and continued throughout pregnancy ${ }^{(1)}$. Advancement of pregnancy is accompanied by the extra demand of energy. As pregnancy progresses, a wellintegrated metabolic shift occurs to ensure an adequate supply of nutrients to a constantly feeding fetus from an intermittently fasting and feeding mother. During this period a woman is subjected to a lot of nutritional, metabolic, hormonal and physiological demands and regulations. Nutritionally she requires enhanced inputs with respect to calories, macro and micro nutrients (2). As the metabolic activities are triggered the demand of oxygen is also increased and oxidation of reducing equivalents in electron transport chain (ETC) is enhanced. Various redox systems of electron transport chain and other redox systems are active. In this process there is a likely-hood of developing reactive oxygen species as free radicals ${ }^{(4)}$. During pregnancy the demand for energy and oxygen requirement is high ${ }^{(5)}$. This leads to intake and utilization of oxygen resulting in increased levels of oxidative stress and the acceleration in the production of reactive oxygen species. 
Vitamin $\mathrm{C}$ is a potent reducing agent, meaning that it readily donates to recipient molecules. Related to this oxidation-reduction potential, two major functions of Vitamin $\mathrm{C}$ are as an antioxidant and as an enzyme cofactor ${ }^{(6,7)}$. Vitamin $C$ is the primary water-soluble, non-enzymatic antioxidant in plasma ${ }^{(6,7)}$. Even in small amounts vitamin $\mathrm{C}$ can protect indispensable molecules in the body like proteins, lipids, carbohydrates and nucleic acids (DNA and RNA) damage by free radicals and reactive oxygen species. Vitamin C's role as a cofactor is also related to its redox potential. Vitamin $\mathrm{C}$ is helpful in prevention of many diseases like Cardiovascular disease, Hypertension, various types of Cancers ( breast cancer, stomach cancer, colon cancer, NonHodgkin lymphoma), Alzheimer's disease, Cataract and Gout . Vitamin C affects several components of the human immune system for example Vitamin C stimulates both the production $(8-12)$ and function ${ }^{(13,14)}$ of leukocytes especially neutrophils, lymphocytes and phagocytes.

The study is to estimate the concentration of Vitamin $\mathrm{C}$ in all the three trimesters of normal pregnant women and to compare it with non pregnant women.

\section{Materials and Methods}

A total number of 200 women, 150 pregnant and 50 non pregnant with an age ranging from 20-35 years were selected for the study. Among 150 pregnant women, 50 in number were included in each trimester forming three categories A, B and C depending upon the type of trimester first, second or third. Category D included non pregnant women. The serum Vitamin C concentration was measured in all these 200 women. The study was conducted over a period of nine months. The following criteria was used for exclusion:

1. Family and personal history data of Diabetes, Jaundice and Hypertension

2. Pregnancy toxaemia

3. Asthma

4. Renal disease

5. Cancer

6. Coronary heart disease

7. Alzheimer's disease

The study was done from July 2015 to April 2016 at Arth Diagnostics Private Limited, Udaipur. The blood of the subjects was collected between 8:00 A.M. and 10:00 A.M. after an overnight fast of at least ten hours. The serum was extracted immediately and analysed for Vitamin C levels. The analysis was done by HPLC (High Pressure Liquid Chromatography) method. The laboratory reference ranges were $2-14 \mathrm{mg} / \mathrm{L}$ for serum Vitamin C.

\section{Results}

The serum concentration of Vitamin $C$ in 150 pregnant women forming category $\mathrm{A}, \mathrm{B}$ and $\mathrm{C}$ with respect to trimester first, second and third were significantly lower as compared to category $\mathrm{D}$ (control group) including the non pregnant women as shown in Table I. Average total Vitamin $\mathrm{C}$ concentration in the first trimester was $43.6 \%$ less than the control group. Similarly, total Vitamin $\mathrm{C}$ concentration in the second trimester was $60 \%$ less than the control and in the third trimester it was $77.6 \%$ less than the control. In all the completed trimesters, there is significant reduction in values of vitamin $\mathrm{C}$ than control non pregnant group ( $\mathrm{p}$ value $<0.05)$.

Table I: Total serum Vitamin C concentration in the three trimesters of pregnancy and in the non pregnant women

\begin{tabular}{|l|l|l|l|l|}
\hline & Category A & Category B & Category C & Category D \\
\hline & First Trimester & Second Trimester & Third Trimester & Non pregnant \\
\hline & & & & Control Group \\
\hline & Mean \pm SD & Mean \pm SD & Mean \pm SD & Mean \pm SD \\
\hline Vitamin C Values & $2.82 \pm 0.61$ & $2.0 \pm 0.86$ & $1.12 \pm 0.5$ & $5.0 \pm 0.15$ \\
\hline
\end{tabular}




\section{Discussion}

Vitamin $\mathrm{C}$ is essential nutrient required for a range of essential metabolic reactions, collagen synthesis, wound healing and as an antioxidant agent. Well known syndromes caused by Vitamin $\mathrm{C}$ deficiency include scurvy and increased risk of atherosclerosis. In case of Vitamin $\mathrm{C}$ deficiency, the body stores are consumed and depleted first, hence, the time required for onset of symptoms of deficiency can be variable depending on the baseline body stores and associated stressful/disease conditions. As dicussed, pregnancy is associated with increased requirement for dietary energy as a result of an elevated metabolic rate (16) due to increased oxygen comsumption and utilization. The accelerated oxygen intake has been shown to lead to increased levels of oxidative stress via production of highly toxic reactive oxygen species (3).If left unchecked, reactive oxygen species inflict a constant barrage of oxidative damage to DNA, proteins and lipids (17). Evidence supporting this excessive reactive oxygen species production and accompanying oxidative stress during pregnancy include studies reporting low superoxide dismutase activity, low vitamin $\mathrm{E}$ and increased serum concentration of products of lipid peroxidation. The progressive decline in serum Vitamin C concentration observed in this study may be due to increased utilization of Vitamin $\mathrm{C}$ by pregnant women for scavenging of reactive oxygen species and maintenance of healthy pregnancy, as it is considered as a strong antioxidant. Besides the increased oxidative stress Vitamin C deficiency among pregnant women affects placental structure leading to placental infection both of which results in increased risk of premature rupture of placental membranes and premature births. Further deficiency can cause serious health complications in the fetus' brain. Ordinarily there is selective transport from mother to fetus of the substances the baby needs during pregnancy. However, it now appears that the transport is not sufficient in the case of Vitamin C deficiency .Therefore the need for Vitamin $\mathrm{C}$ supplementation is very essential throughout the entire period of pregnancy. In addition the supplementation could help to prevent the development of such complications of pregnancy like gestational hypertension, intrauterine growth retardation and gestational diabetes, all known to be associated with high levels of oxidative stress.

\section{Conclusion}

Serum Vitamin C concentration were observed to be low in pregnant women in all the three trimesters when compared with non-pregnant women. Among all the trimesters, Vitamin C concentration was found to be lowest in the third trimester. Therefore, supplementation of Vitamin $\mathrm{C}$ during the entire period of pregnancy is recommended in order to avoid the complications associated with Vitamin $\mathrm{C}$ deficiency during pregnancy.

\section{References}

1. Deepak Parchwani and Disha Patel. Status of Lipid Profile in Pregnancy. Natural Journal of Medical Research. 2011. 22492295.

2. Renata, G., K. Miroslow, K. Wlodizimierz, K. Ryszard and S. Ewa, 2002. Changes in antioxidant components in blood of mares during pregnancy and after foaling. Bull Vet Inst Pulaway, 46: 301-5.

3. Agarwal, A and S.S. Allamaneni, 2004. Role of free radicals in female reproductive diseases and assisted reproduction. Reprod Biomed Online, 9: 338-47.

4. Morris,J.M., N. K. Gopaul, M.J. Enderson, M. Knight, E.A. Linton, S. Dhir,E. E. Anggard and C.W. Redman,1998. Circulating markers of oxidative stress are raised in normal pregnancy and preeclampsia. Br. J. Obstet Gynaecol., 11: 1195-9.

5. Butte, N.F., W. W. Wong, M.S. Treuth, K.J. Ellisand S. E. O’Brian, 2004. Energy requirements during pregnancy based on total energy expenditure and energy deposition. Am. J. Clin Nutr., 79: 1078-87 
6. Combs J, Gerald F. The Vitamins. 4 ed. Burlington: Elsevier Science; 2012.

7. Erdman JW, MacDonald I, Zeisel SH, International Life Sciences Institute. Present knowledge nutrition. $10^{\text {th }}$ ed. Ames, lowa: International Life Sciences Institute; 2012.

8. Prinz W, Bortz R, Bregin B, Hersch M. The effect of ascorbic acid supplementation on some parameters of the human immunological defence system. Int J Vitam Nutr Res. 1977; 47 (3): 24 (Pubmed).

9. Vallance S. Relationships between ascorbic acid and serum proteins of the immune system. 1977; 2( 6084): 437-438( Pubmed).

10. Kennes B, Dumont I, Brohee D, Hubert C, Neve P. Effect of vitamin $C$ supplements on cell immunity in old people. Gerontology. 1993; 29 (5): 305-310. (Pubmed).

11. Panush RS, Delafuente JC, Katz P, Johnson J. Modulation of certain immunologic response. Potentiation of in vitro and in vivo lymphocyte responses. Ins J Vitam Nutr Res Suppl. 1993.

12. Jariwala RJ, Harakeh S. Antiviral and immunomodulatory activities of ascorbic acid. In: H; Subcellular Biochemistry. Vol. 25. Ascorbic Acid: Biochemistry and Biomedical Cell Biology.

13. Levy R, Shriker O, Porath A, Riesenberg $\mathrm{K}$, Schlaeffer F. Vitamin $\mathrm{C}$ for the treatment of furunculosis in patients with impaired neutrophil functions. J Infect Dis. 1996; 173(6): 1502-1506. (Pubmed).

14. Anderson R, Oosthuizen R, Maritz R, Theron A, Van Rensburg AJ. The effects of increasing doses of ascorbate on certain cellular and humoral immune functions in normal volunteers. Nutr. 1980; 33(1): 7176. (Pubmed).
15. Agarwal, A., R. A. Saleh and M.A. Bedaiway, 2003. Role of reactive oxygen species in the athophysiology of human reproduction. Fertil Steril, 79:829-43.

16. Casanueva, E. And F. E. Viteri, 2003. Iron and oxidative stress in pregnancy. J. Nutr., 133:5: 1700S-1708S.

17. Lof, M., H. Olausson, K. Bostrom, B. Janerot-Sjoberg, A. Sohlstrom and E. Forsum, 2005. Changes in basal metabolic rate during pregnancy in relation to changes in body weight and composition, cardiac output, insulin -like growth factor I and thyroid hormones in relation to fetal growth. Am. J. Clin Nutr., 81: 678-85.

18. Qanungo, S. and M. Mukherjea, 2005. Ontogenic profile of some antioxidants and lipid perioxidation in human placental and fetal tissues. Mol Cell Biochem., 215:11-19.

19. Uotila, J., R. Tuimala, T. Aarnio, K. Pyykko and M. Ahotupa, 1991. Lipid peroxidation products, selenium-dependent glutathione peroxidise and Vitamin $\mathrm{E}$ in normal pregnancy. Eur. J. Obstet Gynaecol. Repreduc Biol., 42:95-100.

20. Evans RM, Currie L, Campbell A. The distribution of ascorbic acid between various cellular components of blood, in normal individuals, and its relation to the plasma concentration. $\mathrm{Br} \mathrm{J} 1982 ; 47(3)$ : 473-482. (Pubmed). 